\title{
Covid-19 and Kawasaki Disease: A Glimpse at the Past for a Predictable Future
}

\author{
Giovanni Battista Calabri ${ }^{1} \cdot$ Roberto Formigari $^{2}[$
}

Received: 10 May 2020 / Accepted: 23 May 2020 / Published online: 27 May 2020

(c) Springer Science+Business Media, LLC, part of Springer Nature 2020

During the early phase of the Covid-19 outbreak, the focus was to prevent infection and to care for the most fragile patients at risk for death, the elderly and the ones with severe comorbidities. Children seemed to be relatively safe, with only minor symptoms and a swift recovery.

Now, a major warning is spreading all over the world about the increasing occurrence of Kawasaki Disease (KD) among children living in high-risk areas, potentially linked with the coronavirus infection [1]. Several international scientific societies issued an alert due to the increase, in the past 3 weeks, in the number of children with a "multi-system inflammatory state requiring intensive care" $[2,3]$.

This should come as no surprise.

It was a cluster of patients with "mucocutaneous lymph node syndrome" presenting after an outbreak of coronavirus rhinitis which prompted Dr. Tomisacu Kawasaki to think of a correlation between the viral infection and the obscure disease which will bear his name (personal interview with Dr. Kawasaki by one of the authors, G.B.C.). Indeed, 40 years later, Esper et al. noted that among eleven consecutive patients with $\mathrm{KD}$, eight had Coronavirus-positive nasal swabs [4]. Further studies failed to prove the presence of the Coronavirus in acutely ill KD patients but, since the infection may act just as the initial trigger for an immunemediated self-sustained disease, the virus may have disappeared long before the onset of the KD symptoms.

Moreover, there is some evidence that the "Covid-19-associated" disease may present as an atypical form of KD [4]. In this view, we think the term "Covid-19-associated vasculitis" as a much more appropriate term for this disease, rather than "Covid-19-associated KD". These two similar but distinct entities may even coexist since the "true" KD has the highest incidence in March-April.

In this view, the former confidence of children being protected from the Covid-19 sounds even more incautious. Perhaps, better knowledge of the literature and of Medical History could have made it possible to predict this severe complication of the Covid-19 infection.

\section{Compliance with Ethical Standards}

Conflict of interest G.B. Calabri and R. Formigari declare that they have no conflicts of interest.

Ethical Approval This article does not contain any studies with human participants or animals performed by any of the authors.

\section{References}

1. Jones VG, Mills M, Suarez D et al (2020) COVID-19 and Kawasaki disease: novel virus and novel case. Hosp Pediatr. https://doi. org/10.1542/hpeds.2020-0123

2. https://picsociety.uk/wp-content/uploads/2020/04/PICS-state ment-re-novel-KD-C19-presentation-v2-27042020.pdf

3. https://www.sip.it/wp-content/uploads/2020/04/COVID-19-eMK_lettera-SIP_carta-intestata-1.pdf

4. Esper F, Shapiro ED, Weibel C, Ferguson D, Landry ML, Kahn JS (2005) Association between a novel human coronavirus and Kawasaki disease. J Infect Dis 191:499-502

Publisher's Note Springer Nature remains neutral with regard to jurisdictional claims in published maps and institutional affiliations.

Roberto Formigari

roberto.formigari@opbg.net

1 Department of Pediatric Cardiology, “A. Meyer” Pediatric Hospital, Firenze, Italy

2 Department of Pediatric Cardiology and Cardiac Surgery, "Bambino Gesù" Pediatric Hospital, Rome, Italy 